\title{
How the Pedagogist Practices His Profession on Couple and Family Problems
}

\author{
Franco Blezza* \\ Department of Philosophical, Pedagogical and Economic-Quantitative Sciences DPPEQS of the University Gabriele d'Annunzio, Italy
}

*Corresponding author: Franco Blezza, Department of Philosophical, Pedagogical and Economic-Quantitative Sciences DPPEQS of the University Gabriele d'Annunzio, Italy

\section{Abstract}

Pedagogy is a social science whose origins refer to classical Greece, and it is also for its own nature a social profession, with neighboring foundations in the nineteenth century Mitteleuropa, whose apical professional is called "Pedagogist", properly. Italy has given recently legal recognition to the professional Pedagogist (law 205/2017, art. 1 594-601). In this essay we take in synthetic examination the profile of this social professional and of some important examples of the rich and diversified "toolbox" that he can use in its practice, in a composite culture and relevant for its differentiated inputs and their integration, with particular regard to the professional practising for couple and family problems. We can understand also the reasons why the historical dimension is so important, necessary, to the training of the Pedagogist like to every pedagogy student
\end{abstract}

Keywords: Pedagogist; social professions; professional Pedagogy; Sozialpädagogik; helping relationship; couple; family

\section{Introduction}

\section{Aim, pedagogist is a professional in Italy too}

In December 2017 the Italian Parliament approved definitively the law 205, that introduces a first definition and discipline of the profession of Pedagogist, so finally aligning Italy with Europe and Occident at this specific regard, and giving to the pedagogical culture the recognized and ruled professionality that have long existed for Medicine and Surgery, Engineering, Law, Economics and Commerce, Chemistry, Physics, Social service, and so on. The aim of this paper is to summarize some aspect of this profession, his toolbox and his practice, particularly on couple and family problems Blezza [1].

\section{Pedagogy: the science and the social profession}

The pedagogist is the professional of the highest level expressed by the pedagogical culture and the complex of educational subjects and sciences. Such a professional, like any other, is susceptible to specializations and hierarchical articulation. It is a profession of ancient history as those of the medical surgeon and of the jurist, about 2500 years in Western civilization. On the other hand, education is an essential human necessity as well as the health and the civil coexistence normed by positive law. The historians of pedagogy, and those of thought, know how and why in certain periods the integral fulfilment of such a need may not have the necessity of a specific professional contribution, even though the education always was the subject of study and reflection. The profound change in the time of the pedagogical professions should be placed in relation to the different educational paradigms that prevailed in each historical period, just as was the case for the professional contribution of the jurists. The social role of the medical doctor and surgeon, on the contrary, has had a much more complex history and was characterized by the constancy of a substantial presence and a strong social conspicuousness. John Dewey (1859-1952) defined the Sophists "the first body of professional educators in Europe" [2]. And it is of great interest the context of this affirmation, a particular perspective of the relationship between pedagogy and philosophy The earlier history of philosophy, developed by the Greeks in Asia Minor and Italy, so far as its range of topics is concerned, is mainly a chapter in the history of science rather than of philosophy as that word is understood to-ay. It had nature for its subject and speculated as to how things are made and changed. Later the traveling teachers, known as the Sophists, began to apply the results and the methods of the natural philosophers to human conduct. When the Sophists instructed the youth in virtue, the political arts, and the management of city and household, philosophy began to deal with the relation of the 
individual to the universal, to some comprehensive days, or to some group; the relation of man and nature, of tradition and reflection, of knowledge and action. Can virtue, approved excellence in any line, be learned, they asked? What is learning? It has to do with knowledge. What, then, is knowledge? How is it achieved? Through the senses, or by apprenticeship in some form of doing, or by reason that has undergone a preliminary logical discipline? Since learning is coming to know, it involves a passage from ignorance to wisdom, from privation to fullness from defect to perfection, from non-being to being, in the Greek way of putting it. [2], Chapter Twenty-four: Philosophy of Education] The term "pedagogy" and derivatives where unused in the Dewey's English language, compared to the term "education", unlike for other western languages such as German, French, Italian and several others ones; moreover, the English language is knowing its evolution also in this specific regard. And let us not forget that the fundamental work of Dewey of the 1897 , collection of five essays, was entitled My pedagogic creed [3].

\section{In the XIX century's Mitteleuropa there are the neigh- boring roots for intellectual professions of the $\mathrm{XX}$ cen- tury}

Some professions that have gained great importance in the XX century have had their foundations in the context of the Mitteleuropa, in the European world of German-speaking, or in its vicinity, in the previous century: particularly the professions of the psychological and psychoanalytic area, and the professions of sociological culture. The modern era had ended since the last decades of the XVIII century with the Enlightenment, the bourgeois revolutions, the industrial revolution and the deep social changes that have been achieved. It was starting a later historical era, which has no unique denomination and that was dominated by a certain Biirgergeist that had in the education an essential foundation: an education carried out through the replication of prefixed models, and aimed at the construction of the genders in an extremely polarized sense as required by the "nuclear" family paradigm, a very important creation of that period. Such an educational investment was very strong but a-specific, did not required the Pedagogist's help to have a particular pedagogical culture, but only the previous adherence to those principles, and the consequent commitment to replicate everything ion their own students Blezza [4]. Those ideas spread quickly in Europe; and die Wiener Kongress with the pretended Restoration of the ancien régime appears to us an illusory attempt to let the clock of history go back. The social, cultural and economic reality had deeply changed and began to evolve, it would immediately take frantic rhythms as they were never seen before. The figure of Johann H. Pestalozzi (1746-1827) qualify the exit from the Enlightenment in Pedagogy. He was a pedagogist in the full sense, since he has always been in direct and organic relationship with the reality of education, engaged in the agricultural colony and then for the orphans and as a teacher, but with an original theorical synthesis that developed contextually, well documented by his scientific works. Two were the main Pedagogists who continued his work: Friedrich Fröbel (1782-1852), who devoted himself to der
Kindergarten, i.e. to the childhood school, and Johann F. Herbart (1776-1841) who theorized pedagogy as a synthesis of ethics and psychology, a few years before psychology came out of philosophy

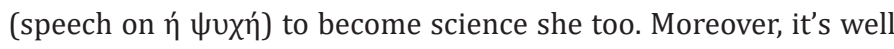
known that all the sciences have been philosophies and have preserved one or more philosophies in their essence. At that point, there were all the assumptions for the profession of pedagogist had a firm reference also in the same historical and cultural context Mitteleuropean, and particularly in the Sozialpńdagogik Blezza [5] See the bibliographies enclosed in these books of the author of this paper]. We are referring to the work of researchers pedagogists as Karl Mager (1810-1858), who first wrote of "sozial Pädagogik" in 1844 (in the "Pädagogische Revue" of which he was director from 1840 to 1848); he proposed this conceptuality as opposed to Individual-Pädagogik and alternatively to Collectivpädagogik; Friedrich A. W. Diesterweg (1790-1866), who dealt with the training of the teachers, and was critic of the notionism and favourable to a school for the people, and who first of all developed the concept of learning by doing; and Paul Natorp (1854-1924) who introduced first the term compound in the essay entitled precisely Sozialpädagogik (the subtitle evoked a theory of the desires that come from the basis of the community established in the common culture, or Gemeinschaft [6]. Public domain in the web, where we can find several other articles and short essays]. A particular importance must be bestowed, or given back, to the specifically pedagogical contribution of Émile Durkheim (1858-1917), let's not forget that the great scientist of the society began his academic career at the University of Bordeaux in 1887 with the call to the chair of Social sciences and Pedagogy, and was then called to the Sorbonne, where he entered in 1902, in 1906 as professor on the chair of Pedagogy, and that only in 1913 would assume the name of Pedagogy and Sociology. He was not only a great social Pedagogist, he was one of the founders of Sociology, and this historical qualification perhaps leads to not giving the right importance to others; In fact, he was also an Anthropologist and a researcher on religions. His pedagogical works were mostly gathered from articles and dispenses in posthumous volumes, from which it is evident its importance; the Web makes the right homage to a great Pedagogist and allows a specific study. They were not, in short, minor works [for instance Durkheim [7-11]. They are comprehensive tides. However, even in works classified as more specific in Sociology or other social sciences, the tenet of Pedagogy is highly appreciable. These documents are widely available in the public domain of the Web]. Among other things, his birth in Alsace-Lorraine and the unmistakable origin of the surname (das Heim indicates in German the home, family, of origin ...). They concur with that idea which we have mentioned, i.e. the fundamental importance of the mitteleuropean culture for the foundation of a complex of sciences that would have given rise to a wide range of intellectual and social professions in the twentieth century. This is it not an isolated case: Pedagogy is a science, a social science, fully fledged; and it's not just a philosophical science anymore. And a particular importance must be given, or restored, to the specifically pedagogic contribution of Émile Durkheim. 


\section{A New Branch of General Pedagogy}

We will call professional Pedagogy a particular branch of general Pedagogy Blezza . This branch deals with the study, the proposal and the experimentation of principles, methods, techniques, procedures, specific vocabulary and the related organic arrangement for the specifically pedagogical professional practice. In a nutshell, everything that constitutes a necessary condition for a pedagogical profession and for the community of professional Pedagogists. The essential contribution of professional Pedagogy is also indicated for initial and continuous training of intellectual professionals in the social and health sectors, in the School and in the psychological field. We must widely explore the contribution it can make to the professionalism of the university professor, researchers and students, regardless of the sector in which they are framed. As for general Pedagogy, and for any branch of this social science, the development of professional Pedagogy must be in an organic relationship with the reality object of studies and applications, and must maintain it, also in order to obtain the necessary experiential feedback that, as is known from the Epistemology of the XIX and $\mathrm{XX}$ centuries. This observance of the experience following is a condition of the scientificness of the discourse, and therefore, inter alia, of intersubjective transferability of every discourse, which in education is indispensable, of openness and respect of the person. These are also indispensable conditions in education, towards a

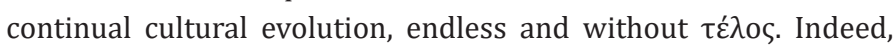
any idea, proposition, human creation, hypothesis, alternative we propose within the professional Pedagogy, as in the general Pedagogy, is nevertheless subjected to what Pragmatists have taught us to call the "future experience". Karl R. Popper resumed this conceptuality, and it is appropriate to read fully its statute of das Abgrenzungskriterium, which is well-known: Nun wollen wir aber doch nur ein solches System als empirisch anerkennen, das einer Nachprüfung durch die "Erfahrung" fahig ist. Diese Überlegung legt den Gedanken nahe, als Abgrenzungskriterium nicht die Verifizierbarkeit, sondern die Falsifizierbarkeit des Systems vorzuschlagen; mit anderen Worten: Wir fordern zwar nicht, daß das System auf empirisch-methodischem Wege endgiiltig positive ausgezeichnet werden kann, aber wir fordern, daß es die logische Form des Systems ermoglicht, dieses auf dem als Abgrenzungskriterium Wege der methodischen Nachpriifung negative auszuzeichnen: Ein empirisch-wissenschaftliches System muß an der Erfahrung scheitern konnen [12], edition on the Web, 6. Falsifizierbarkeit als Abgrenzungskriterium.] It follows that Pedagogy is a science / Wissenschaft stricto sensu, also according to this Abgrenzungskriterium: a social science, as it develops through a constant position of problems and a continuous attempt to solve them through human creativity, expressed respecting the rules of inner coherence and external consistency, and any other typical rule of science. Professional Pedagogy is a branch in dose relation, strongly synergistic with the branch of Sozialpàdagogik, also for the historical reasons that have been mentioned. Particularly important is the rethinking of Popper about fifty years after the basic work just mentioned, following the formulation of Tichý's theorem, on the question of very similitude [Tichý [13]; Bartley III, Popper [14]; Rosicka, Svoboda, Jespersen and Cheyne [15]. We can't speak of some form of progress in the evolution of scientific knowledge and, more generally, of human knowledge: this concept is consistent with today's Pedagogy, which, moreover, not long ago, recognizes in cultural evolution an ateleological process which has no fixed direction but only one verse, that of the time's arrow, that of the increase of global entropy, that of the "clock of history" whose hands, as is known and as already said, "can't go back". Social and professional Pedagogy to aid the couple and the family. Presentation of this second part of the paper. The aim of these remaining pages will be to report synthetically and organically what has been studied, proposed and experienced in social and professional Pedagogy about problems of couple, family and parenthood, and the decision associated with these fundamental instances of sociality.

\section{The abduction, cases and casuistries, examples}

Abduction (ab-ductio, $\alpha \pi \alpha \gamma \omega \gamma \eta \dot{)}$ s a tipical way from particular to general cases, in continuous research, by the professional Pedagogist as by other professionals. First of all, no professions are given without adequate competence on the theories and general cases that the practicer has the task of treating: so, in the human physiology and pathology of the doctor surgeon, as for those of the animals of the veterinarian, as for the pharmacological principles of the pharmacist, or as for the science of constructions and for the other technical disciplines of the architect and civil engineer, et coetera. The professional competence is highlighted in the specific modality in which the transition from the particular to the general is accomplished: the simplest and most immediate example is that of the medical doctor, who cures sick and don't cure sicknesses, each case with its singular and unfailing peculiarities, but could not cure them if it does not bring back the clinical frame of each individual sick to the general case of the sickness, such as diagnosis, prognosis and therapy. This necessary human mediation, which does not give certainty, from the logical point of view does not constitute a tautology but a form studied since antiquity: it can be called abduction or retro-duction. $\mathrm{h}$ is one of the underlying concepts of the composite contribution to the Pragmatism of Charles S. Peirce (1839-1914), to whom we must the first theorization of science as fallibilism. In the proper field or dominium of the social and professional Pedagogy, with particular regard to the problems of couples, partnership and family, a passage of foundamental importance consists in helping the interlocutors to bring to the explicit what of their respective life projects is long been implicit, or other-wise not expressed and not discussed, as deemed not in need of any analysis, as taken for granted, as it is assumed tacit and perpetual acceptance on the part of the partner without any legitimacy. A typical casuistry for this specific matter concerns a profound asymmetry between the two partners in the "outside" investment, work social relations and public roles, and the "interior", family intimacy and the domestic home: one of the two partners who, at the moment of the contraction of the bond, 
are invested with wide-ranging "outside", and the other "inside", even in full harmony and in agreement. At a time not far away, the first person was necessarily the male and the second one the female; and for this determination natural causes and motives would be given. Today there are increasing reciprocal choices. It is often noted that one of the two partners conceives this balance in diversity as definitive and pacifically accepted by the other one forever, and the other partner considers it only a temporary and conditioned step, for example, until the partner has achieved some social status or until the children have reached a certain age. At that point, that of the two partner who had accepted the preminent investment "inside" begin to recapture its "outside" spaces, e.g. by rescuing its own study degrees and professional qualifications, opening free-trade or crafts or social cooperatives; to that, it happens that the other Partner refuses to rebalance the situation and considers this behaviour as a kind of breach of commitments, commitments that have never been taken. Something similar also happens in the sex life: certain sexual behaviours can be held for years, with one of the two partners who decides to accept them only provisionally, while the other believes that the acceptance is definitive, forever, and without any exception. For example, one of the two accepts contraceptive behaviours in the other considering them provisional, while the other has not posed any term for these practices. Often this is not discussed unless after a long repetition of this sexual practice conditioned by a unilateral decision, until it is much more difficult to intervene if it is still possible. Even about fidelity, there are those who believe that the other partner accepts unquestionably his treacheries without in turn betray: in this case too, it would be the male towards the female in times past, today happens the reciprocal also. In this and in all the other examples of casuistries that could be brought these beliefs that emerge only after many years, sometimes after decades, in their disruptive character for the couple, were given to tacitly accepted and for not requiring any discussion from the beginning of the life of that couple. We must add, for the professional experience that we have done, that where there is full and unreserved opening on the part of both partners cases like these are all solvable with mutual satisfaction and without residue, even when the behavior of the one or of the other or of both have taken breaking or even dramatic features. The mind

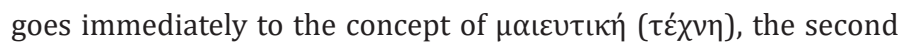

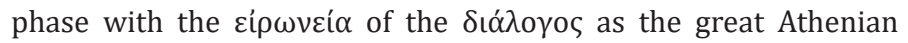
$\Sigma \omega \kappa \rho \alpha ́$ ins proposed, a give birth to what has matured inside the interlocutor also making him face the difficulties connected. That can be as painful as childbirth pains. This juxtaposition is correct, but with the important difference of not having any claim to reach some $\alpha \lambda \eta^{\prime} \theta \varepsilon \iota \alpha$. On the other hand (here and elsewhere), this is accomplished without any involvement of the unconscious, being ideas perfectly conscious even if not discussed and implied, and without the slightest possibility that the professional intervention of the Pedagogist can be confused with a form of therapy. It is, on the contrary, a helping relationship that compared to the therapy is an exclusive alternative: not to cure someone or something, but to care of someone or something, or more directly and generally following I care! of Martin Luther King. We are talking about a professional intervention with the word, but not a "therapy of the word". After pointing out all these concepts, we can outline some phases in logical and methodological sequence that effectively describe and scan the relevant professional practice.

\section{Problem Posing}

So much for the general features of a reflective experience. They are

a) perplexity, confusion, doubt, due to the fact that one is implicated in an incomplete situation whose full character is not yet determined;

b) a conjectural anticipation - a tentative interpretation of the given elements, attributing to them a tendency to effect certain consequences;

c) a careful survey (examination, inspection, exploration, analysis) of all attainable consideration which will define and clarify the problem in hand;

d) a consequent elaboration of the tentative hypothesis to make it more precise and more consistent, because squaring with a wider range of facts;

e) taking one stand upon the projected hypothesis as a plan of action which is applied to the existing state of affairs: doing something overtly to bring about the anticipated result, and thereby testing the hypothesis.

It is the extent and accuracy of steps three and four which mark off a distinctive reflective experience from one on the trial and error plane. They make thinking itself into an experience. Nevertheless, we never get wholly beyond the trial and error situation. Our most elaborate and rationally consistent thought must be tried in the world and thereby tried out. And since it can never take into account all the connections, it can never cover with perfect accuracy all the consequences.

These words where written over a century ago [Dewey 2016, Chapter Eleven: Experience and Thinking]. Living and operating "by problems" was already clearly ruled even through the consequent stages. For the continuation of the speech, we owe much to Popper regarding the philosophy of science [Since the Logik der Forschung, $1934 / 35$, that, we observe this choice carefully, did not bear the adjective "wisseschaftilche". This adjective will only appear in the English edition], although he preferred to call it "logic of research", and to George Polya (1887-1985), initially in the field of didactics of mathematics [the fundamental work is from [16]. Notable, among others, are also Polya $[16,17]$ and then also of the teaching of physics and natural sciences Mathematical Methods in Science (Mathematical Association of America, [18]). Among his works in the Italian edition, there is also Mathematical methods for the teaching of the physical sciences Zanichelli, Bologna [19]. Following again the Logik der Forschung, the problem has its logical definition as a contradiction between established assertions, between two theories, or between a theory and an assertion describing a fact. Thus, the "problem" acquires an essential function for the evolution of the knowledge and for the human life: it is, in short, a positive 
factor, while the term has in the common language a negative inflection, as if we wanted a life without problems, that is a life impossible and without evolution. Compared to these positions, and compared to others also, are at least two the changes that are proposed today in social and professional pedagogy. A first change concerns the precise distinction that must be established between the situation of imbalance, contradiction, conflict, difficulties that the living being one encounters in its interaction with the environment and with the other living ones, which we would call rather "problematic situations", distinct from the "problem" properly said. Between the ones and the other there is the human decision, which is not automatic or mechanical, but on the contrary, is highly selective: only a very few problematic situations become problems, a small minority. We would call then "problem" the rationalization of a problematic situation, namely the positive, constructive reaction of the man who intends to overcome what he always meets, ordinarily, commonly of non-harmonic in his interaction with the environment [20]. For instance, the couple is in a highly problematic situation: are they willing to make it a problem? The second change warns that the human reaction in posing the problem doesn't have in itself any guarantee of success, and it would be for a naively optimistic reading of these messages, confused with simplistic assertions of some obscure and crude positivists in the XIX century. On the contrary, theories are human creations: all that is assumed and elaborated in an attempt to solve the problem is imperfect and fallible, like any human artefact. In other words: what do you do when you have posed a problem? The correct answer is not "I solve it", but "I try to solve it", "I devise a solution hypothesis".

\section{Theories, coherences, evolutions}

After the problem has been posed, or rather already in the act of the position of the problem, it is then involved the very high human faculty that is creativity. During about two centuries, this general faculty was considered under the romantic and idealistic impulse of "genius and lack-of-rules". I.e. it was denied to almost all human persons. On the contrary, any social instance starting with the couple and the family, is constantly a continual source of problematic situations, the most important of which must be posed as a problem and therefore js involved the practice of creativity. This creativity, in turn, is not unregulated, its practice is always normed, and here too there would be heavy criticisms to address to the culture and education of the XIX and XX centuries.

In a nutshell, and referring to other works for the appropriate insights, the hypotheses created, devised and proposed in an attempt to solve human problems must be subjected to certain orders of rules of method, at least if we speak on pedagogy, on social sciences and on social service, on human relationship interpersonal, on civil and democratic coexistence. We synthesize these rule's orders below.

a) Hypotheses are to be inserted into broader thought environments, otherwise they have neither Sinn, nor meaning nor applicability. It is what one does with the scientific hypotheses which are inserted in laws, theories, branches and disciplines, both in the sciences of nature and in the sciences human, social and of culture.

b) These hypotheses, with all the context in which they are inserted, must be subject to the rules of inner coherence i.e. the Logic; for education we must highlight the rule of non-contradiction. Both Pragmatists and Popper, and much of the epistemology of the XX century, indicated to use the so-called "classical" logic, Aristotelian systematized in the Middle Ages by Thomism. The Pragmatists and, among them, the physician and psychologist William James believed that this logic was inscribed in the anatomy and physiology of the human brain; Popper instead adopted it because binary, that is because it's the strongest.

c) The "inner" coherence is not enough, it comes sooner or later the moment in which it is necessary to test the advanced hypotheses, together with the whole system of thought within which they was developed, and thus is consequently required the "external" coherence; as it was clear to the Pragmatists. Popper theorized rigorously that there is no inductive method, there is no possibility of making "true" a hypothesis for how many positive confirmations it receives from experience, while only one empirical falsification is sufficient to logically affect the hypotheses and the whole system in which it was inserted.

d) We could continue for a long time, but in summary we conclude this review with the application to human things of an authentic historical and critical spirit, whereby every hu $\neg$ man idea, by the fact that it is human, is subject to becoming historical, which does not represent an incoherence, and it is always susceptible to criticism from those who advanced it and from anyone else.

e) Ideas are for man, and never man for ideas. In family too, or better starting right from the couple and the family.

f) We respect, and we can also admire, those who dedicate their lives to an idea, even when it is observed that the maintenance to the deeper end of that idea ends up butting or with the rules of inner coherence, and here we are at the socratic ei $\rho \omega v \varepsilon i ́ \alpha$, or with those of external coherence, reality contrasts falsifications of fact to those convictions, and in any case are violated in principle the rules of human historicity and of criticism.

What is not to be respected, and indeed whose condemnation does not allow exceptions, is any behaviour, in any place or entity, that tends to enslave other people or person to an idea, especially people who, for some reason, are in a situation of less strength or dependence: children compared to parents, elderly and disabled compared to people in the fullness of their resources, those who ask for help, those who need assistance, and so on. Here we must pay dose attention, because in most cases the violation of this fundamental rule takes on lies and noble appearances: it's commonly replied that some people are enslaved to the ideas of others "for their own higher interest", "for the good of the family" or "to save the family", "for the good of the company", "for the work of everyone", "for the good of the players before the team", and so continuing, in short for a non-personal but more general, superior 
good or interest. You must not fall into any of these pitfalls or other comparable analogues, the answer can only be negative: the human person can never be made an instrument by others for any idea, however high the nobility and human valence are alleged about that idea. In short, the person can never be made an instrument for any purpose and for any condition: it is always and only a purpose to itself.

\section{Psychology as a science of education for the profession- alism of the pedagogist}

The composite character of the general Pedagogy, and therefore also of the social and professional Pedagogy, allows to transpose within these domains the contributions coming from other disciplinary fields and from authors pertaining to them that they would never consider themselves Pedagogists; obviously, it must be done after reprocessing these contributions in order to integrate them with the complex of pedagogical-general and pedagogicalsocial and professional culture, and after turning to the specific aims of education that are not the aims of all those disciplines, or of others yet. In this analysis we can't go beyond an extremely concise and schematic scanning: family and couple problems are fields of explication in many respects exemplary. We could and should begin with Sigmund Freud (1856-1939) and Psychoanalysis, except that for us Pedagogists the unconscious is a precluded domain: precluded by the awareness of not having the skills to enter the unconscious, before the laws that protect the exercise of certain professions or therapeutic arts, and anyway by the fact that we are not therapists. We could continue talking about other Psychoanalysts, including the founders of other fundamental schools of Psychoanalysis: Jung, Adler, Lacan. A very important contribution comes to us from Erich Fromm (1900-1980), for example with the concepts of "paternal" love and "maternal" love that should be balanced and integrated, without which opens the way to one side for a whole series of pathologies that are not our competence, on the other for a whole series of educational shortcomings that instead directly involves our competences. But many others are the contributions that come to us from this important social psychologist, as, moreover, from the whole Frankfurter Schule at the Goethe Universität to which he too referred: from criticism to civilisation and contemporary society, to the study of aggression, the destructiveness and the necrophilia, until the discourse on the modalities of having and being. Understandably, fundamental is the contribution of Carl Rogers (1902-1987), where we consider carefully also in this case that our competences are not therapeutic. We practice the helping relationship and, so working, we have very much to learn from him. Instead, we can fully employ the conceptual tools proposed by Viktor Frankl (1905-1997), namely the search for Lebenssinn, die Dereflexion, der paradoxen Intention and der gemeinsame Nenner. Just as it can be fully employed by the professional Pedagogist das Autogene Training according to J.H. Schultz (1884-1970), especially when considering die Formel, the fundamental propositional formula original, poorly successful translation of "(Ich bin) ganz ruhig [ruhe]" and recourse to it, rather than as a simple technique of relaxation, for specifically pedagogical reasons with a propositional alternative formula studied for the purpose, for example for the utmost effort in study, in work, in sport, in artistic activity; in the pursuit of maximum concentration; for the overcoming of personal fears and obstacles; for liberation from addictions and risky behaviours; and in practice in almost every purpose that one could put in hypothetical way in a pedagogical intervention as such.

\section{And back over the millennia to the instruments of clas- sical Greece}

Of course, in 2500 years and more of history of Pedagogy we have to analytically collect a huge collection of ideas, conceptual and operational tools, procedures, lexical forms for the profession of pedagogist. We could start with the Greeks, but without neglecting the Latins, beginning with their philosophies and literatures but not neglecting the ancient science and technique, first of all as methodology of interaction with the natural reality and with the social reality. These methodologies are widely misunderstood today, but they can teach us a lot with a direct access two millennia and more before Galileo, Gilbert, modem science i.e. the science of the modem era. On the other hand, Frankl himself considered direct descendants of the Socratic dialogue not only his own logoanalytical technique, but all the Psychoanalysis and any form of therapy by the word; To that same ancient classical source we draw us with the pedagogical interlocution and other forms of clinical colloquium, as in the rest draw to the Greek-dassical sources for a whole other

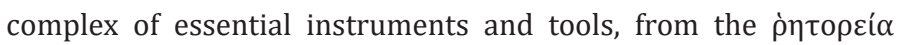

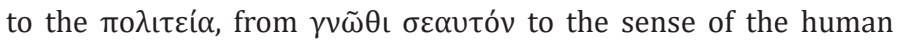
limit with the condemnation of the ǔßpıs, and away continuing for a long time. The important choice, as has been said, is to not scotomize all the other immense contributions that we can derive from classical Latinity as well as from Greece, and the scientific and technical contributions in relation to the philosophical and literary ones, moreover, thus avoiding a rift in the classical culture that has no historical or scientific legitimacy. However, what has been summarized and exemplified here can make a sufficiently substantial and organic idea of the profession of Pedagogist and of its culture to wide spectre, which we could also represent with the metaphor of a "toolbox" of a variety and richness that amazes even the most experienced scientists and professional in the specific field of social sciences and professions.

\section{Deliveries to the professional practice, a very particular sort of conclusion}

The undeniably empirical nature of Pedagogy, which must be developed in an organic relationship with the educational experience and with the reality object of study and applications, is coherent with the etymon of the term designating this social science of man: a Latin etymon, straddling the middle era and the modem era: Paedagogia as "Paedagogi ars", the art of taking charge, of caring, education in people who must be educated as social subjects. The fact that, then, the Latin word "paedagogus" was a transposition of the Greek term $\pi \alpha \iota \delta \alpha \gamma \omega \gamma$ ós, and that this

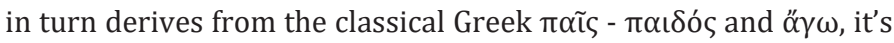
a different discourse. There existed in the classical Greek also the 


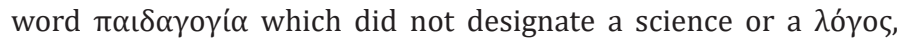
but the activity of that particular subject who was instructed by the father to accompany the young people, the sons, on the social occasions more favourable for their education which were offered by the $\pi$ ó $\lambda ı s$, especially at its $\alpha \gamma \omega \rho \alpha$, place of primary sociality. Not by chance, this suffix "-agogy" finds in pedagogy, and in its subsidiaries sciences "andragogy" and "geragogy", these lasts are words rarely used in Italian and in other languages, a real ö $\pi \alpha \xi$ $\lambda \varepsilon \gamma o$ orvov among the denominations of sciences and professional disciplines. As known, the main choice go for the suffix "-logy". The medical doctors surgeons for their specialties prefer the suffix "-iatry" i.e. therapy, even if they don't miss the suffixes "-logy" (audiology, gynaecology, cardiology, ...) and other different choices still (optics, radio diagnostics, childcare, obstetrics, ENT, ...) as well as various compound words and phrases referring to surgery. This speech is of particular interest, because it explains how Pedagogy cannot be a simple "-logy" i.e. a speech without commitment and application, and in no case is it a "-iatry" i.e. a therapy [21]. As for any empirical science of nature, or for any social science of culture, no study can close with a simple conclusion, but it must pass the discourse to the future experience and his feedbacks, in our case of course a professional practice experience, of a helping relationship towards subjects in problematic situations, for example for being in a couple or in a family.

\section{References}

1. Blezza F (2018) Pedagogia professionale. Che cos'è, quali strumenti impiega e come si esercita. Limena (PD): Libreria Universitaria, Italy.

2. Dewey J (1916) Democracy and Education: An Introduction to the Philosophy of Education. New York: Macmillan, USA.

3. Dewey J (1897) My pedagogic creed, School journal. New York and Chicago: EL Kellog \& Co 54: 77-80.

4. Blezza F (2005) Studiamo l'educazione oggi. Venosa: Osanna, Italy.

5. Blezza F (2010) La pedagogia sociale. Che cos'è, di che cosa si occupa, quali strumenti impiega. Napoli: Liguori, Italy.
6. Natorp P (1899) Sozialpildagogik. Theorie Der Willenserziehung Auf Der Grundlage Der Gemeinschaft, Forgotten Books, UK.

7. Dewey J (1938) Logic the Theory of Inquiry. New York NY: Henry Holt and Company, USA.

8. Durkheim DÉ (1902-1903) L'éducation morale. Cours de sociologie dispensé à la Sorbonne. Paris : Librairie Félix Alcan.

9. Durkheim, DÉ (1904-1905) L'évolution pédagogique en France, Cours pour les candidats à l'Agrégation dispensé en. Paris, 1re édition, 3e trimestre.

10. Durkheim DÉ (1922) (première édition) Éducation et sociologie. Paris : Les Presses universitaires de France.

11. Durkheim DÉ (1924) Sociologie et Philosophie. Paris : Librairies Félix Alcan.

12. Popper KR impressum tätskhlich (1934-1935) Logik der Forschung - Zur Erkenntnistheorie der modernen Naturwissenschaft. Wien: Springer-Verlag.

13. Tichý P (1974) “On Popper's definitions of Verisimilitude." The British Journal for the Philosophy of Science 25(2): 155-160.

14. Bartley III, W.W. ed. (1982-1983) Postscript to the Logic of Scientific Discovery by Karl R. Popper. Vol. I Realism and the Aim of Science, Vol. II The Open Universe, Vol. III Quantum Theory and the Schism in Physics. London, Hutchinson.

15. Rosicki Z, Svoboda V, Jespersen B, Cheyne C, eds. (2004) Pavel Tichýs' Collected Papers in Logic and Philosophy. Dunedin: Prague and Otago University Press, New Zealand.

16. Polya G (1945) How to solve it - A new aspect of mathematical method. Garden City, New York, Doubleday and Co. Inc, USA.

17. Polya G (1962) Mathematical Discovery: on understanding, learning, and teaching problem solving, 2 vols. New York: Wiley and Sons, USA.

18. Polya G (1977) Mathematical methods for the teaching of the physical sciences. New York, Mathematical Association of America, USA.

19. Boas ML (1979) Mathematical methods for the teaching of the physical sciences. Bologna: Zanichelli, Italy.

20. James W (1890) The principles of Psychology. 2 vols, New York: Henry Holt and Co, USA.

21. Peirce CS (1931-1958) Collected Papers, 8 vols. Cambridge Massachusetts: Harvard University Press, USA.
CC (P) This work is licensed under Creative Commons Attribution 4.0 License

To Submit Your Article Click Here: Submit Article

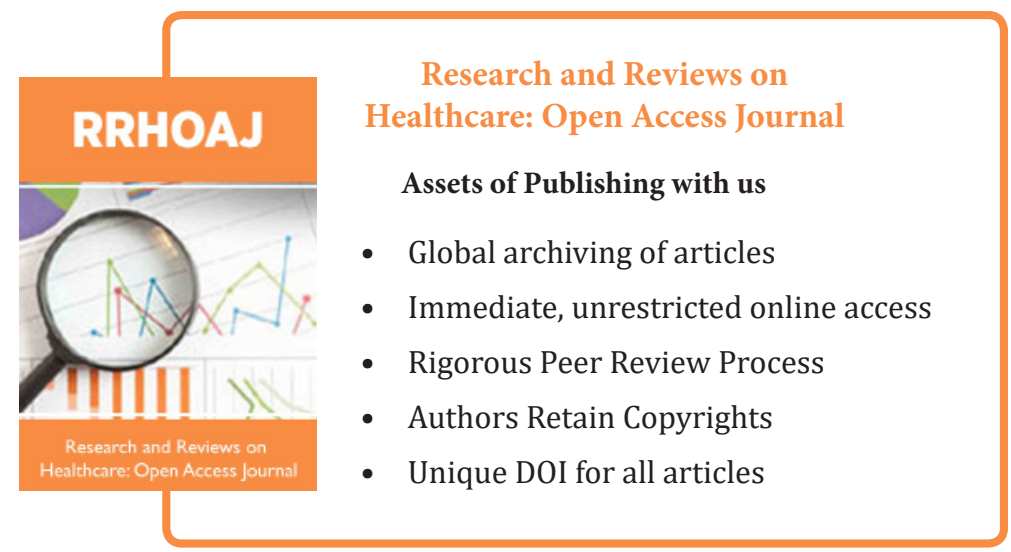

